Original Research Article

\title{
Tracing Styphnolobium japonicum (syn: Sophora japonica) as a potential adulterant of ginkgo-containing foods by real-time PCR
}

\author{
Liliana Grazina ${ }^{\mathrm{a}}$, Joana S. Amaral ${ }^{\mathrm{b}}$, Joana Costa ${ }^{\mathrm{a}}$, Isabel Mafra ${ }^{\mathrm{a}, *}$ \\ ${ }^{a}$ REQUIMTE-LAQV, Faculdade de Farmácia, Universidade do Porto, Rua de Jorge Viterbo Ferreira, 228, 4050-313, Porto, Portugal \\ ${ }^{\mathrm{b}}$ Centro de Investigação de Montanha (CIMO), Instituto Politécnico de Bragança, Campus de Sta. Apolónia, 5301-857, Bragança, Portugal
}

\section{A R T I C L E I N F O}

\section{Keywords:}

Styphnolobium japonicum

Species-specific detection

Ginkgo biloba

Real-time PCR

Quantification

Authenticity

Adulteration

Herbal infusions

\begin{abstract}
A B S T R A C T
The rising demand for ginkgo-containing products and their high economic value make them desirable targets for adulteration, particularly by the partial substitution with other plant species. Styphnolobium japonicum (plant rich in flavonol glycosides) is known as a potential adulterant of ginkgo-based foods. Therefore, this work aimed at developing a species-specific real-time polymerase chain reaction (qPCR) method for the identification/quantification of $S$. japonicum as an adulterant of ginkgo-containing products. The method used the EvaGreen dye, targeting the internal transcribed spacer 2 (ITS2) region of $S$. japonicum, providing acceptable performance parameters and a sensitivity down to $0.02 \mathrm{pg}$ of DNA. Moreover, a qPCR assay was established using binary mixtures of $S$. japonicum in $G$. biloba, covering the dynamic range of $50-0.05 \%(w / w)$ of added adulterant. After trueness evaluation with blind samples, the approach was applied to 21 commercial herbal infusions, from which one was positive to $S$. japonicum, but below the limit of quantification $(0.05 \%)$, suggesting its inadvertent contamination rather than adulteration. To the best of our knowledge, for the first time, a specific method was proposed to quantify potential adulterations of $G$. biloba products with $S$. japonicum, providing an accurate and cost-effective tool to authenticate ginkgo-containing herbal foods.
\end{abstract}

\section{Introduction}

Ginkgo biloba L. (known as ginkgo), a millenary Chinese tree also known as a living fossil, is one of the most popular medicinal plants for its beneficial activity in brain function. Currently, ginkgo is reported as one of the most popular botanicals used in plant food supplements (Garcia-Alvarez et al., 2014; Clarke et al., 2015), being legally considered as foods under the Directive, 2002/46/EC and the Dietary Supplement Health and Education Act (DSHEA) (FDA, 2019). Therefore, it is widely present as an ingredient in several food products, such herbal infusions and plant food supplements. Besides, it has been used by the pharmaceutical industry in the form of standardised extracts with $\geq 24$ $\%$ of flavonol glycosides and $\geq 6 \%$ of terpene lactones (Ma et al., 2016). The consumption of these products has been increasing over the last decade in European countries and USA, which is probably related with the rising number of elderly suffering from cognitive impairment and mild dementia due to the average life expectancy increase, as well as to a growing number of consumers that want to improve general brain health and memory. The well-established biological effects of ginkgo in improving age-associated cognitive impairment and minor circulatory disorders are attributed to the presence of pharmacologically active compounds, particularly the flavonol glycosides and the terpene lactones (Booker et al., 2016; EMA, 2015; Gafner, 2018; WHO, 2004; Wohlmuth et al., 2014).

The rising sales of ginkgo herbal products and ever-growing demand for plant material resulted on its worldwide price increase, thus turning this species a desirable target of economically motivated adulteration. Up until now, several studies have shown ample evidences of fraud in G. biloba supply chains (Avula et al., 2015; Collins et al., 2020). The most frequently reported concern either the addition of pure flavonols/flavonol glycosides or the total/partial replacement of gingko by other plant species rich in those compounds, but of lower economic value. Among these, Styphnolobium japonicum (L.) Schott (syn: Sophora japonica L.) has been referred as the most frequently used as G. biloba substitute

Abbreviations: PCR, Polymerase chain reaction; qPCR, quantitative real-time polymerase chain reaction; ITS, Internal transcribed spacer; HPLC, High performance

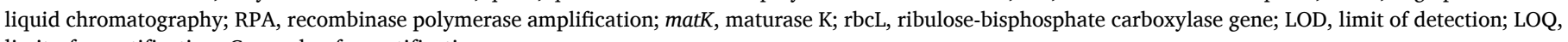
limit of quantification; Cq, cycle of quantification.

* Corresponding author.

E-mail address: isabel.mafra@ff.up.pt (I. Mafra). 
Table 1

Data of primers used, targeting the ITS2 region of $S$. japonicum and a conserved eukaryotic region.

\begin{tabular}{|c|c|c|c|c|c|}
\hline Species & Target & Primer & Sequence $\left(5^{`} \rightarrow 3^{`}\right)$ & Length & Reference \\
\hline \multirow{2}{*}{ S. japonicum } & \multirow{2}{*}{ ITS2 } & Styj3-F & CACGATGGATGGTGGCTGAG & \multirow{2}{*}{$110 \mathrm{bp}$} & \multirow{2}{*}{ This work } \\
\hline & & Styj3-R & TCTCGTTATGGGGCGATCGTA & & \\
\hline \multirow{4}{*}{ Eukaryotes } & \multirow{4}{*}{ Nuclear 18S rRNA } & 18SRG-F & CTGCCCTATCAACTTTCGATGGTA & \multirow{2}{*}{$113 \mathrm{bp}$} & \multirow{2}{*}{ Costa et al. (2013) } \\
\hline & & 18SRG-R & TTGGATGTGGTAGCCGTTTCTCA & & \\
\hline & & EG-F & TCGATGGTAGGATAGTGGCCTACT & \multirow{2}{*}{$109 \mathrm{bp}$} & \multirow{2}{*}{ Villa et al. (2017) } \\
\hline & & EG-R & TGCTGCCTTCCTTGGATGTGGTA & & \\
\hline
\end{tabular}

in food supplements (Avula et al., 2015; Budec et al., 2019; Gafner, 2018; Govindaraghavan, 2018). S. japonicum is used in traditional Chinese medicine for its haemostatic properties and has been described as a commercial source of rutin owing to its high levels in flowers and buds (Kite et al., 2009). This species is particularly suited to carry out such adulteration because its fruits are rich in flavonoid glycosides that tend to overlap with those of ginkgo (Govindaraghavan, 2018).

Currently, methods described in ginkgo quality control monographs rely mainly on the determinations of the ratios of flavonol aglycones (quercetin, kaempferol, and isorhamnetin) by high performance liquid chromatography (HPLC) after an acidic hydrolysis step and subsequent calculation of flavonol glycosides (Ma et al., 2016). However, such approaches can be inadequate when applied to formulations that include mixtures of plant species and can also fail to detect the addition of similar extracts from other plant sources. Alternatively, DNA-based techniques are highly suitable tools for species identification, with different works demonstrating their usefulness in the authentication of herbal infusions and plant food supplements (Costa et al., 2016; Grazina et al., 2020a, b). These methodologies take advantage of the high specificity of the DNA molecules, which exist in all plant cells and are independent from environmental, physiologic and storage conditions, allowing to overcome some limitations of the chemical methods (Costa et al., 2015; Ganie et al., 2015; Soares et al., 2015; Techen et al., 2014). So far, different DNA-based approaches have been reported aiming the specific identification of $G$. biloba in herbal products, namely DNA barcoding applied to dietary supplements (Little, 2014; Pawar et al., 2017), next generation sequencing applied to products containing ginkgo extracts or plant material plus extract (Ivanova et al., 2016) and real-time polymerase chain reaction (PCR) for the specific detection of G. biloba in natural health products (Dhivya et al., 2019) and herbal infusions (Grazina et al., 2020b). However, the detection of $S$. japonicum as ginkgo's adulterant has been reported only in one previous work. Liu et al. (2018) reported a recombinase polymerase amplification (RPA) approach relying on the use of species-specific primers and a probe with high specificity for the detection of both $G$. biloba and $S$. japonicum in herbal products. Nevertheless, the method does not allow for quantification and cross-reactivity testing with several other plant species was rather limited. Thus, in this work, a simple quantitative real-time PCR (qPCR) method using the EvaGreen dye was proposed and validated to detect and quantify $S$. japonicum as an adulterant in ginkgo-containing foods. The method was further applied to several ginkgo-based herbal infusions broadly available in the global market to assess any eventual substitution of $G$. biloba by $S$. japonicum.

\section{Materials and methods}

\subsection{Plant species, commercial samples and model mixtures}

Styphnolobium japonicum leaves and voucher seeds were kindly provided by the Botanical Garden of University of Trás-os-Montes e Alto Douro (UTAD) (Vila Real, Portugal) and University of Arizona Herbarium/Boyce Thompson Arboretum (USDA-Grin, Tucson, AZ, USA), respectively, while $G$. biloba leaves were from the Botanical Garden of University of Porto (Porto, Portugal). A total of 21 samples of ginkgo herbal infusions were acquired at the local market, specialised herbal stores and e-commerce.

Seeds were grinded with a mortar, while the leaves and herbal infusions were grinded in a laboratory mill Grindomix GM200 (Retsch, Haan, Germany). Biological material of several plant species including medicinal and aromatic plants, spices and fruits were also used to for cross-reactivity testing (Table S1).

For the method development, model mixtures with $50 \%, 10 \%, 5 \%$, $1 \%, 0.5 \%, 0.1 \%, 0.05 \%$ and $0.01 \%(\mathrm{w} / \mathrm{w})$ of $S$. japonicum in G. biloba were prepared, using both species in the form of powdered leaves. Moreover, for trueness evaluation, four blind mixtures were also prepared $(20.0 \%, 8.0 \%, 2.0 \%$ and $0.2 \%(\mathrm{w} / \mathrm{w})$ of $S$. japonicum in G. biloba).

\subsection{DNA extraction and quality assessment}

DNA was extracted from $50 \mathrm{mg}$ of powdered plant material using the NucleoSpin Plant II kit (Macherey-Nagel, Düren, Germany), according to the manufacturer's instructions with slight modifications, as described by Costa et al. (2016).

Yield and purity of the DNA extracts were evaluated by UV spectrophotometry, using a Synergy HT multi-mode microplate reader (BioTek Instruments, Inc., Winooski, VT) with a Take3 micro-volume plate accessory and the nucleic acid quantification protocol for double-strand DNA in the Gen5 data analysis software version 2.01 (BioTek Instruments, Inc.). After quality assessment, all the extracts were kept at $-20{ }^{\circ} \mathrm{C}$ until further analysis.

\subsection{Oligonucleotide primers}

In silico analysis was performed using the basic local alignment search (BLAST) (https://blast.ncbi.nlm.nih.gov/Blast.cgi) and PrimerBLAST (https://www.ncbi.nlm.nih.gov/tools/primer-blast/) tools to verify the specificity of the target fragment and primers, respectively. The designed specific primers for S. japonicum (Styj3-F/Styj3-R) targeted the internal transcribed space 2 (ITS2) of nuclear ribosomal DNA (GenBank accession: HQ229005.1). Properties of the primers were checked using the OligoCalc software (http://www.basic.northwestern. edu./biotools/oligocalc.html) to guarantee the absence of primer hairpins and self-hybridisation. The presence of amplifiable DNA was confirmed using two universal eukaryotic primer pairs (18SRG-F/ 18SRG-R and EG-F/EG-R), targeting a conserved $18 \mathrm{~S}$ rRNA nuclear region (Costa et al., 2013; Villa et al., 2017). The primers were synthesised by Eurofins MWG Operon (Ebersberg, Germany) and are presented in Table 1.

\subsection{End-point PCR}

PCR amplification was carried out using $2 \mu \mathrm{L}(20 \mathrm{ng})$ of DNA extract in a total reaction volume of $25 \mu \mathrm{L}$ containing buffer $(67 \mathrm{mM}$ Tris- $\mathrm{HCl}$, $\mathrm{pH} 8.8,16 \mathrm{mM}\left(\mathrm{NH}_{4}\right)_{2} \mathrm{SO}_{4}, 0.01 \%$ Tween 20$), 3 \mathrm{mM}$ of $\mathrm{MgCl}_{2}, 1.0 \mathrm{U}$ of SuperHot Taq DNA Polymerase (Genaxxon Bioscience GmbH, Ulm, Germany), $200 \mathrm{nM}$ of each primer (Styj3-F/Styj3-R), and $200 \mu \mathrm{M}$ of each dNTP (Grisp, Porto, Portugal). The reactions were performed in a MJ Mini ${ }^{\mathrm{TM}}$ Gradient Thermal Cycler (Bio-Rad Laboratories, Hercules, CA, USA) with the following temperature program: initial denaturation 
at $95{ }^{\circ} \mathrm{C}$ for $5 \mathrm{~min} ; 40$ cycles of amplification at $95^{\circ} \mathrm{C}$ for $30 \mathrm{~s}, 59^{\circ} \mathrm{C}$ for $30 \mathrm{~s}$, and $72{ }^{\circ} \mathrm{C}$ for $30 \mathrm{~s}$; final extension at $72{ }^{\circ} \mathrm{C}$ for $5 \mathrm{~min}$.

PCR products were analysed by electrophoresis in a $1.5 \%$ agarose gel containing $1 \times$ Gel Red (Biotium, Inc., Hayward, CA, USA) for staining and carried out in $1 \times$ SGTB buffer (GRISP, Porto, Portugal) running $20-25 \mathrm{~min}$ at $200 \mathrm{~V}$. The agarose gel was visualised under a UV light tray Gel Doc ${ }^{\mathrm{TM}}$ EZ System (Bio-Rad Laboratories, Hercules, CA, USA) and a digital image was recorded using Image Lab software version 5.2.1 (Bio-Rad Laboratories, Hercules, CA, USA).

\subsection{Real-time PCR}

The qPCR assays were carried out in a total reaction volume of $20 \mu \mathrm{L}$, containing $2 \mu \mathrm{L}(20 \mathrm{ng})$ of DNA, $1 \times$ SsoFast $^{\mathrm{TM}}$ EvaGreen ${ }^{\circledR}$ Supermix (Bio-Rad Laboratories, Hercules, CA, USA), $300 \mathrm{nM}$ of each primer (Styj3-F/Styj3-R) (Table 1). A fluorometric thermal cycler CFX96 Realtime PCR Detection System (Bio-Rad Laboratories, Hercules, CA, USA) was used under the following conditions: $95^{\circ} \mathrm{C}$ for $5 \mathrm{~min}$; 45 cycles at $95^{\circ} \mathrm{C}$ for $15 \mathrm{~s}$ and $63^{\circ} \mathrm{C}$ for $45 \mathrm{~s}$, with collection of fluorescence signal at the end of each cycle. For melting curve analysis, the PCR amplicons were denatured at $95{ }^{\circ} \mathrm{C}$ for $1 \mathrm{~min}$ and then annealed at $63^{\circ} \mathrm{C}$ for $3 \mathrm{~min}$ to allow the correct annealing of the DNA duplexes. Afterwards, the temperature was increased from $63{ }^{\circ} \mathrm{C}$ to $95{ }^{\circ} \mathrm{C}$ with increments of $0.2{ }^{\circ} \mathrm{C}$ every $5 \mathrm{~s}$, with acquisition of fluorescence signal at the end of each melting temperature. Data were processed using the software BioRad CFX Manager 3.1 (Bio-Rad Laboratories, Hercules, CA, USA). Each sample was analysed in, at least, four replicates in two independent runs.

\section{Results and discussion}

\subsection{Selection target region and evaluation of the oligonucleotide's specificity}

Several regions, including nuclear and plastid regions such as matK, $r b c L$, ITS1 and ITS2, have been previously proposed as plant barcodes (Grazina et al., 2020b; Hollingsworth et al., 2009, 2011). Among them, the nuclear ITS region has been described as a valuable DNA barcode for molecular authentication of plant species due to its high interspecific divergence and high discrimination power over plastid regions (Li et al., 2015). Moreover, the ITS2 region has already been suggested as a universal DNA barcode for the differentiation of plant species because it presents enough variability to distinguish even closely related species, being generally a region of easy amplification (Yao et al., 2010). Therefore, in this work, the nuclear ITS2 region was chosen to design specific primers for $S$. japonicum to allow the amplification of a short fragment of $110 \mathrm{bp}$ (Styj3-F/Styj3-R). The optimised species-specific PCR reached a sensitivity down to $0.002 \mathrm{pg}$ of $S$. japonicum DNA (supplementary Fig. S1).

The absence of sequence homology with other species was verified using the BLAST tool, while the primer specificity was checked with the Primer-BLAST tool. The primer specificity was further assayed using DNA extracts obtained from several plant species, including medicinal plants, fruits and spices, among others, confirming the absence of amplification (supplementary Table S1). Before cross-reactivity testing, the amplification capacity of DNA extracts was verified by PCR targeting a eukaryotic fragment, as described by Costa et al. (2013).

\subsection{Real-time PCR}

\subsubsection{Method development}

After demonstrating the adequacy of the new primers for the specific identification of $S$. japonicum DNA, a qPCR method using EvaGreen dye was developed. Comparing with the oligonucleotide probes, the universal dyes offer a greater flexibility and reduced cost, allowing also to verify the reaction specificity by means of the dissociation (melt) curve analysis of the PCR products. EvaGreen is a new generation fluorescent
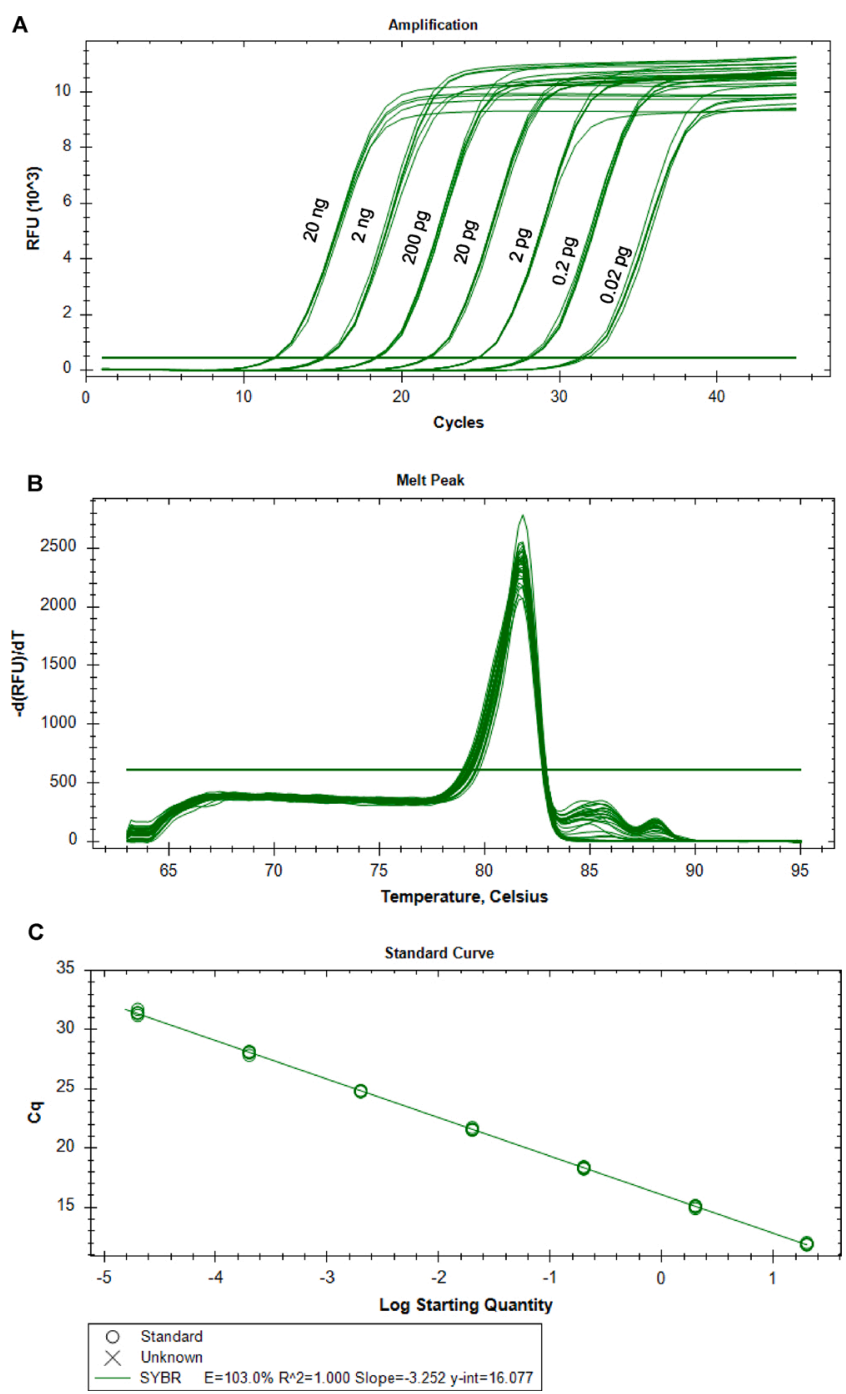

Fig. 1. Amplification (A), melting (B) and calibration (C) curves of a real-time PCR assay with EvaGreen ${ }^{\circledR}$ dye, targeting the ITS2 region of $S$. japonicum. The amplified extracts were obtained from 10 -fold serially diluted $S$. japonicum DNA from $20 \mathrm{ng}$ to $0.02 \mathrm{pg}$ ( $n=5$ replicates).

DNA-binding dye that offers several advantages over the widely used SYBR Green I dye. Enhanced fluorescence of dsDNA binding products, excellent stability and ability to be used at high concentration without inhibiting the PCR are among the superior features of the EvaGreen dye, which results in high reaction efficiencies (Eischeid, 2011). These unique properties allow for increased sensitivity and make EvaGreen dye particularly suited for qPCR.

For method development and validation, the acceptance criteria established for qPCR assays were carefully considered, namely the slope within -3.6 and -3.1 , the PCR efficiency between $90-110 \%$, and the correlation coefficient $\left(R^{2}\right)>0.98$ (Bustin et al., 2009; ENGL, 2015). The limit of detection (LOD) and the limit of quantification (LOQ) were established as the lowest amplified level for $95 \%$ of the replicates and the lowest amplified level within the linear dynamic range of the calibration curve provided the relative repeatability standard deviation is $\leq 25 \%$, respectively. The linear dynamic range of the calibration curve should cover at least 4 orders of magnitude (Bustin et al., 2009; ENGL, 2015).

Before method development, additional cross-reactivity tests were performed by real-time PCR to confirm the specificity of the primers for $S$. japonicum identification as a potential adulterant of $G$. biloba. With this aim, a qPCR amplification was carried out using extracts containing 
A

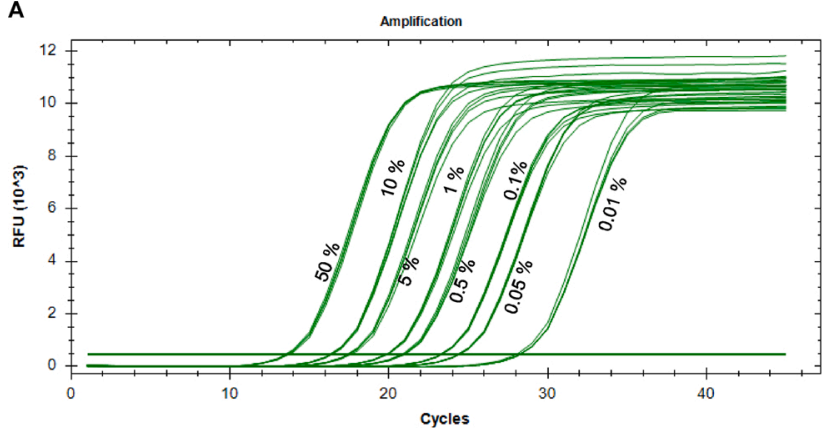

B

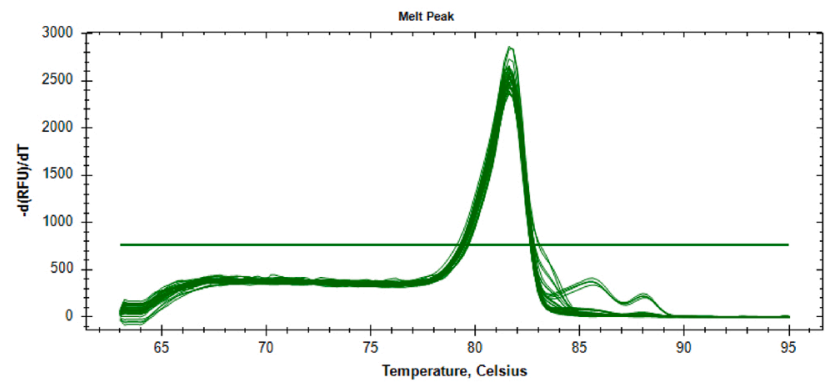

C

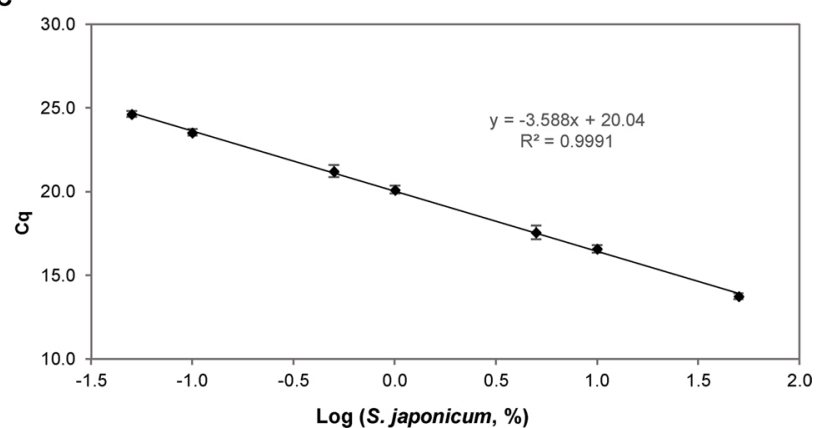

Fig. 2. Amplification (A), melting (B) and calibration (C) curves of a real-time PCR assay with EvaGreen ${ }^{\circledR}$ dye, targeting ITS2 region of $S$. japonicum, using the binary mixtures with $50 \%, 10 \%, 5 \%, 1 \%, 0.5 \%, 0.1 \%, 0.05 \%$ and $0.01 \%$ (w/ w) of S. japonicum in G. biloba (mean values of 6 independent assays in triplicate, $n=18$ ).

$20 \mathrm{ng}$ of each of G. biloba and S. japonicum DNA (corresponding to the higher level of the calibration curve). The results show an unspecific amplification of ginkgo DNA (20 ng), but at much higher Cq (cycle of quantification) values $(\mathrm{Cq}=32.21 \pm 0.09)$ (supplementary Fig. S1) than the same amount of the target $S$. japonicum DNA $(\mathrm{Cq}=12.12 \pm 0.04)$. Therefore, a Cq value of 32.00 cycles was established as a threshold for specificity, allowing to avoid any false-positive.

For method development, a series of 10 -fold serially diluted extracts were prepared covering 8 concentration levels, from $20 \mathrm{ng}$ to $0.002 \mathrm{pg}$ of $S$. japonicum DNA, whose amplification curves are shown in Fig. 1A. The respective melting curves show close profiles and melt peaks of $81.7 \pm 0.1{ }^{\circ} \mathrm{C}$, which are characteristic of the formation of one single type of fragment and indicates the absence of unintended amplicons (Fig. 1B). The amplification of all replicates $(n=10)$, in two independent assays allowed establishing an absolute LOD of $0.02 \mathrm{pg}$ $(\mathrm{Cq}=31.43 \pm 0.20)$ of $S$. japonicum DNA. The lowest tested level of $0.002 \mathrm{pg}(\mathrm{Cq}=34.87 \pm 1.01)$, though still amplifying all replicates, it could not be considered as LOD because the obtained Cq values were above the established threshold of specificity. The LOQ value was considered the same as the LOD since it was within the dynamic range of the calibration curve, having a relative repeatability standard deviation of $0.64 \%$, thus much below the acceptance criteria ( $\leq 25 \%$ ) (Fig. 1C).
Table 2

Results of the trueness evaluation of the method based on the application of the developed quantitative PCR system to blind mixtures of S. japonicum in G. biloba.

\begin{tabular}{lllll}
\hline \multirow{2}{*}{ Blind Mixtures } & \multicolumn{2}{l}{ Styphnolobium japonicum $(\%, \mathrm{w} / \mathrm{w})$} & \multirow{2}{*}{$\mathrm{CV}^{\mathrm{b}}(\%)$} & Error $^{\mathrm{c}}(\%)$ \\
\cline { 2 - 3 } & Real value (\%) & Estimated value & \\
& & & & \\
\hline SG_A & 20.0 & $18.3 \pm 2.7$ & 14.5 & -8.50 \\
SG_B & 8.0 & $6.80 \pm 1.42$ & 20.9 & -15.0 \\
SG_C & 2.0 & $1.50 \pm 0.18$ & 11.9 & -24.8 \\
SG_D & 0.2 & $0.19 \pm 0.01$ & 6.59 & -3.74 \\
\hline
\end{tabular}

${ }^{\text {a }}$ Mean value \pm standard deviation (SD) $(n=6)$ of two independent assays.

b Coefficient of variation (CV).

${ }^{c}$ Error $=(($ mean estimated value - real value $) /$ real value $)$ x 100.

The average real-time PCR performance parameters of several assays, namely the PCR efficiency $(103.4 \pm 0.5 \%)$, the slope $(-3.244 \pm 0.011)$ and the $R^{2}(0.999 \pm 0.001)$, were all in accordance with the acceptance criteria, as evidenced in the example (Fig. 1C) (Bustin et al., 2009; ENGL, 2015).

Subsequently, aiming at proposing a quantitative model and establishing the relative sensitivity of the method, the binary mixtures containing $50 \%, 10 \%, 5 \%, 1 \%, 0.5 \%, 0.1 \%, 0.05 \%$ and $0.01 \%(\mathrm{w} / \mathrm{w})$ of $S$. japonicum in G. biloba were amplified by real-time PCR (Fig. 2A). The respective melting curve analysis showed the presence of a single melting peak at $81.7 \pm 0.1{ }^{\circ} \mathrm{C}$, which corroborates the suitability of the designed primers, ensuring the absence of primer dimmer (Fig. 2B). To construct the relative standard calibration curve, the obtained Cq values were plotted against the logarithm of the respective relative amounts of S. japonicum (Fig. 2C). The obtained calibration curve shows a high performance of the analytical approach since the mean values of PCR efficiency $(90.0 \%), R^{2}(0.999)$ and slope $(-3.588)$ were all within the acceptance criteria for this type of assays (Bustin et al., 2009; ENGL, 2015). The relative LOD was down to $0.01 \%$ (w/w), while a LOQ of 0.05 $\%$ was established considering the dynamic range of the respective curve, having a relative repeatability standard deviation of $0.72 \%$, which was much below the acceptance criteria $(\leq 25 \%)$.

\subsubsection{Trueness}

For the evaluation of method trueness, four mixtures of $G$. biloba powdered leaves spiked with $20.0 \%, 8.0 \%, 2.0 \%$ and $0.2 \%(\mathrm{w} / \mathrm{w})$ of $S$. japonicum were analysed as blind samples, aiming at evaluating the precision and accuracy of the approach (Bustin et al., 2009; ENGL, 2015). Table 2 shows the results of the estimated relative amounts of $S$. japonicum and the respective actual values. The precision, determined by the coefficients of variation (CV) values (relative standard deviation of results obtained under repeatability conditions), ranged between 6.59 $\%$ and $20.9 \%$, which demonstrates the good precision of the method ( $\leq$ $25 \%$ ) over the considered dynamic range. The measured trueness was expressed as the bias or error between the estimated and the actual values varied from $-3.7 \%$ to $-24.8 \%$, thus being within $\pm 25 \%$ and indicating a good accuracy of the method (ENGL, 2015).

\subsection{Analysis of ginkgo herbal infusions}

The assessment of food authenticity is an issue of increasing concern for governmental bodies, industries and consumers. Herbal infusions are highly consumed and easily available products in the global market, with their formulation frequently including medicinal plants with specific therapeutic effects. Therefore, any adulteration by species substitution will compromise the integrity, and eventually the safety, of the final product, thus making the authenticity assessment of these products of major relevance. To detect possible adulteration with $S$. japonicum, 21 commercial ginkgo-containing herbal infusions were acquired at traditional, specialised and e-commerce stores. After ensuring the presence of amplifiable DNA, each sample extract was amplified by qualitative PCR assay with the new species-specific primers (Styj3-F/Styj3-R). The PCR 
Table 3

Results of commercial samples analysis by end-point PCR and qPCR, targeting the ITS2 region of S. japonicum.

\begin{tabular}{|c|c|c|c|c|c|c|}
\hline \multirow{2}{*}{\multicolumn{2}{|c|}{ Commercial samples }} & \multirow{3}{*}{$\begin{array}{l}\text { Label } \\
100 \% \text { ginkgo }\end{array}$} & \multicolumn{2}{|l|}{ End-point $\mathrm{PCR}^{\mathrm{c}}$} & \multicolumn{2}{|l|}{ qPCR } \\
\hline & & & \multirow{2}{*}{$\begin{array}{l}\text { 18SRG-F/18SRG-R } \\
+\end{array}$} & \multirow{2}{*}{$\begin{array}{l}\text { Styj3-F/Styj3-R } \\
-\end{array}$} & \multirow{2}{*}{$\begin{array}{l}\mathrm{Cq}(\text { mean } \pm \mathrm{SD})^{\mathrm{a}} \\
\mathrm{ND}\end{array}$} & \multirow{2}{*}{$\begin{array}{l}\text { Estimated } S \text {. japonicum } \\
(\text { mean } \pm \mathrm{SD}, \%, \mathrm{w} / \mathrm{w})^{\mathrm{b}}\end{array}$} \\
\hline 1 & Ginkgo tea (leaves) & & & & & \\
\hline 2 & Ginkgo tea (leaves) & $100 \%$ ginkgo & + & - & ND & \\
\hline 3 & Ginkgo tea (leaves) & $100 \%$ ginkgo & + & - & ND & \\
\hline 4 & Herbal infusion (sachets) & $15 \%$ ginkgo & + & - & ND & \\
\hline 5 & Ginkgo infusion (sachets) & $100 \%$ ginkgo & + & + & $>32.00$ & \\
\hline 6 & Ginkgo infusion (sachets) & $100 \%$ ginkgo & + & $+/-$ & $>32.00$ & \\
\hline 7 & Ginkgo tea (leaves) & $100 \%$ ginkgo & + & - & ND & \\
\hline 8 & Ginkgo bio-infusion (leaves) (Agriculture non-EU) & $100 \%$ ginkgo & + & - & ND & \\
\hline 9 & Ginkgo tea (leaves) (Agriculture non-EU) & $100 \%$ ginkgo & + & - & ND & \\
\hline 10 & Tisana MC (Plant mixture) & $15 \%$ ginkgo & + & - & ND & \\
\hline 11 & Tisana TB (Plant mixture) & $15 \%$ ginkgo & + & - & ND & \\
\hline 12 & Ginkgo tea (sachets) & $30 \%$ ginkgo & + & + & $30.50 \pm 0.19$ & $<0.01\left(\mathrm{LOD}^{\mathrm{e}}\right)$ \\
\hline 13 & Ginkgo tea (sachets) & $100 \%$ ginkgo & + & + & $27.28 \pm 0.06$ & $<0.05\left(\mathrm{LOQ}^{\mathrm{f}}\right)$ \\
\hline 14 & Herbal tea (sachets) & Ginkgo (\% not labelled) & + & - & ND & \\
\hline 15 & Herbal tea (sachets) & Ginkgo (\% not labelled) & + & - & ND & \\
\hline 16 & Herbal tea (sachets) & Ginkgo (\% not labelled) & + & - & ND & \\
\hline 17 & Herbal tea (sachets) (Agriculture non-EU) & $15 \%$ ginkgo & + & - & ND & \\
\hline 18 & Ginkgo tea (leaves) & $100 \%$ ginkgo & + & - & ND & \\
\hline 19 & Ginkgo tea (leaves) & $100 \%$ ginkgo & + & + & $29.05 \pm 0.16$ & $<0.01$ (LOD) \\
\hline 20 & Ginkgo tea (sachets) & $100 \%$ ginkgo & + & $+/-$ & $>32.00$ & \\
\hline 21 & Ginkgo tea (leaves) & $100 \%$ ginkgo & + & $+1-$ & $>32.00$ & \\
\hline
\end{tabular}

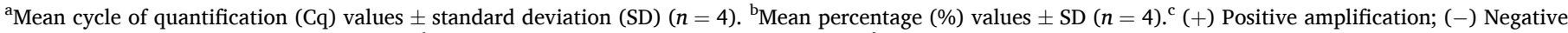
amplification; +/- Doubtful amplification. ${ }^{\mathrm{d}}$ ND, not determined. ${ }^{\mathrm{e}}$ LOD, limit of detection. ${ }^{\mathrm{f}}$ LOQ, limit of quantification.

results showed that 4 out of the 21 commercial samples presented clear positive amplification for $S$. japonicum, while other 3 presented faint bands. To confirm these results and estimate the content of a possible adulterant, the developed qPCR system was applied to the mentioned 7 samples. As it can be observed in Table 3, samples \#5, \#6, \#20 and \#21 should be considered as negative since they presented Cq values above the threshold level (32 cycles), which agrees with the qualitative PCR results. Regarding samples \#12 and \#19, although having Cq values below 32, according to the validated calibration model of Fig. $2 \mathrm{C}$, the estimated $S$. japonicum was below the LOD of $0.01 \%$, thus being considered negative. For the remaining sample \#13 the obtained Cq value was 27.28, corresponding to an estimated value of $0.011 \pm 0.000$ $\%$, which is below the LOQ. Therefore, such trace amount of $S$. japonicum suggest inadvertent contamination rather than a potential adulteration.

\section{Conclusions}

In this work, a qPCR approach using the fluorescent EvaGreen dye was developed aiming at the specific detection and quantification of $S$. japonicum as a potential adulterant of $G$. biloba. The approach targeted the ITS2 region of $S$. japonicum that proved to be a specific marker for this species. The ITS2 marker allowed reliably detecting down to $0.02 \mathrm{pg}$ of $S$. japonicum DNA using both qualitative PCR and qPCR. To develop a quantitative approach, model mixtures of powdered leaves of S. japonicum in G. biloba were prepared and analysed by qPCR, which covered a range from $50 \%$ to $0.01 \%(\mathrm{w} / \mathrm{w})$ of added adulterant. The obtained calibration model provided acceptable performance parameters of PCR efficiency, slope and correlation coefficient, having a LOD and a LOQ of $0.01 \%$ and $0.05 \%$, respectively. The method was successfully validated using four blind mixtures of known composition, showing adequate precision and accuracy. The application of the proposed approach to commercial ginkgo-based herbal infusions showed that out of 21 samples, 7 were suspected as having the $S$. japonicum DNA by qualitative PCR. However, its presence was confirmed in only one sample by qPCR, at a trace levels below the LOQ, suggestion a possible inadvertent contamination, rather than an adulteration.

In summary, the present work proposes a novel, reliable, highly sensitive and specific tool that could be useful to detect potential adulterations of ginkgo-containing herbal products by the control laboratories and regulatory authorities, ensuring their authenticity and safety.

\section{Funding}

The work was supported through the projects UIDB/50006/2020 and UIDB/00690/2020, funded by FCT/MCTES (Fundação para a Ciência e Tecnologia and Ministério da Ciência, Tecnologia e Ensino Superior) through national funds. L. Grazina thanks FCT and ESF (European Social Fund) through POCH (Programa Operacional Capital Humano) for her PhD grant SFRH/BD/132462/2017. J. Costa thanks FCT for funding through program DL 57/2016 - Norma transitória (SFRH/BPD/102404/2014).

\section{CRediT authorship contribution statement}

Liliana Grazina: Methodology, Formal analysis, Investigation, Writing - original draft. Joana S. Amaral: Conceptualization, Supervision, Writing - review \& editing. Joana Costa: Formal analysis, Investigation, Writing - review \& editing. Isabel Mafra: Conceptualization, Funding acquisition, Supervision, Writing - review \& editing.

\section{Declaration of Competing Interest}

The authors declare that they have no conflict of interest.

\section{Acknowledgements}

The authors are grateful for the supply of leaves by the Botanical Garden of University of Porto (Porto, Portugal), the Botanical Garden of UTAD (Vila Real, Portugal), the Botanical Garden of Bern (Bern, Switzerland), the Garden of Serralves (Porto, Portugal) and the Botanical Garden of Madeira, as well as the supply of voucher seeds by the University of Arizona Herbarium/Boyce Thompson Arboretum (USDAGrin, Tucson, AZ, USA) and the RBG (Kew, Ardingly. West Sussex, UK).

\section{Appendix A. Supplementary data}

Supplementary material related to this article can be found, in the 
online version, at doi:https://doi.org/10.1016/j.jfca.2021.103891.

\section{References}

Avula, B., Sagi, S., Gafner, S., Upton, R., Wang, Y.-H., Wang, M., Khan, I.A., 2015. Identification of Ginkgo biloba supplements adulteration using high performance thin layer chromatography and ultra high performance liquid chromatography-diode array detector-quadrupole time of flight-mass spectrometry. Anal. Bioanal. Chem. 407 (25), 7733-7746.

Booker, A., Frommenwiler, D., Reich, E., Horsfield, S., Heinrich, M., 2016. Adulteration and poor quality of Ginkgo biloba supplements. J. Herb. Med. 6 (2), 79-87.

Budec, M., Bosnir, J., Racz, A., Lasic, D., Brkic, D., Cuic, A.M., Kuharic, Z., Jurak, G., Barusic, L., 2019. Verification of authenticity of Ginkgo biloba L. Leaf extract and its products present on the Croatian market by analysis of quantity and ratio of ginkgo flavone glycosides (quercetin, kaempferol and isorhamnetin) to terpene trilactones to the effect of unmasking counterfeit drugs endangering patient health. Acta Clin. Croat. 58 (4), 672-692.

Bustin, S.A., Benes, V., Garson, J.A., Hellemans, J., Huggett, J., Kubista, M., Mueller, R., Nolan, T., Pfaffl, M.W., Shipley, G.L., Vandesompele, J., Wittwer, C.T., 2009. The MIQE Guidelines: minimum information for publication of quantitative real-time PCR experiments. Clin. Chem. 55 (4), 611-622.

Clarke, T.C., Black, L.I., Stussman, B.J., Barnes, P.M., Nahin, R.L., 2015. Trends in the use of complementary health approaches among adults: united States, 2002-2012. Health Stat. Report. (79), 1-16. February 10.

Collins, B.J., Kerns, S.P., Aillon, K., Mueller, G., Rider, C.V., DeRose, E.F., London, R.E., Harnly, J.M., Waidyanatha, S., 2020. Comparison of phytochemical composition of Ginkgo biloba extracts using a combination of non-targeted and targeted analytical approaches. Anal. Bioanal. Chem. 412 (25), 6789-6809.

Costa, J., Oliveira, M.B.P.P., Mafra, I., 2013. Effect of thermal processing on the performance of the novel single-tube nested real-time PCR for the detection of walnut allergens in sponge cakes. Food Res. Int. 54 (2), 1722-1729.

Costa, J., Amaral, J.S., Fernandes, T.J.R., Batista, A., Oliveira, M.B.P.P., Mafra, I., 2015 DNA extraction from plant food supplements: influence of different pharmaceutical excipients. Mol. Cell. Probes 29 (6), 473-478.

Costa, J., Campos, B., Amaral, J.S., Nunes, M.E., Oliveira, M.B.P.P., Mafra, I., 2016. HRM analysis targeting ITS1 and matK loci as potential DNA mini-barcodes for the authentication of Hypericum perforatum and Hypericum androsaemum in herbal infusions. Food Control 61, 105-114.

Dhivya, S., Ragupathy, S., Kesanakurti, P., Jeevitha, S., Noce, I.D., Newmaster, S.G., 2019. Validated identity test method for Ginkgo biloba NHPs using DNA-based species-specific hydrolysis PCR probe. J. AOAC Int. 102 (6), 1779-1786.

Directive 2002/46/EC, 2002. Directive 2002/46/EC of the European Parliament and of the Council of 10 June 2002 on the approximation of the laws of the Member States relating to food supplements (Text with EEA relevance). Off. J. Eur. Commun., L $183,51-57$.

Eischeid, A.C., 2011. SYTO dyes and EvaGreen outperform SYBR green in real-time PCR. BMC Res. Notes 4 (1), 263.

EMA, 2015. Ginkgo Folium - Committee on Herbal Medicinal Products (HMPC/321097/ 2012). Retrieved January 4, 2021 from: https://www.ema.europa.eu/en/m edicines/herbal/ginkgo-folium.

ENGL, 2015. Definition of Minimum Performance Requirements for Analytical Methods of GMO Testing. European Network of GMO Laboratories, Join Research Centre, EURL. Retrieved December 18, 2020 from: https://gmo-crl.jrc.ec.europa.eu/doc /MPR\%20Report\%20Application\%2020_10_2015.pdf.

FDA, 2019. Dietary supplements. Retrieved February 2, 2021 from: https://www.fda. gov/food/dietary-supplements.

Gafner, S., 2018. Adulteration of Ginkgo biloba Leaf Extract, Botanical Adulterants Bulletin, January 2018. Retrieved January 4, 2021 From. http://cms.herbalgram.or g/BAP/BAB/GinkgoBulletin.html.

Ganie, S.H., Upadhyay, P., Das, S., Prasad Sharma, M., 2015. Authentication of medicinal plants by DNA markers. Plant Gene 4, 83-99.
Garcia-Alvarez, A., Egan, B., de Klein, S., Dima, L., Maggi, F.M., Isoniemi, M., RibasBarba, L., Raats, M.M., Meissner, E.M., Badea, M., Bruno, F., Salmenhaara, M., MilàVillarroel, R., Knaze, V., Hodgkins, C., Marculescu, A., Uusitalo, L., Restani, P., SerraMajem, L., 2014. Usage of plant food supplements across six European countries: findings from the PlantLIBRA consumer survey. PLoS One 9 (3), e92265.

Govindaraghavan, S., 2018. Increasing sophistication in adulteration of commercial Ginkgo biloba leaf products: detection using existing methods of analysis of ginkgoflavone glycosides. Fitoterapia 131, 146-159.

Grazina, L., Amaral, J.S., Costa, J., Mafra, I., 2020a. Authentication of Ginkgo biloba herbal products by a novel quantitative real-time PCR approach. Foods 9 (9), 12.

Grazina, L., Amaral, J.S., Mafra, I., 2020b. Botanical origin authentication of dietary supplements by DNA-based approaches. Compr. Rev. Food Sci. Food Saf. 19 (3), 1080-1109.

Hollingsworth, P.M., Forrest, L.L., Spouge, J.L., Hajibabaei, M., Ratnasingham, S., van der Bank, M., Chase, M.W., Cowan, R.S., Erickson, D.L., Fazekas, A.J., Graham, S.W., James, K.E., Kim, K.-J., Kress, W.J., Schneider, H., van AlphenStahl, J., Barrett, S.C. H., van den Berg, C., Bogarin, D., Burgess, K.S., Cameron, K.M., Carine, M., Chacón, J., Clark, A., Clarkson, J.J., Conrad, F., Devey, D.S., Ford, C.S., Hedderson, T.A.J., Hollingsworth, M.L., Husband, B.C., Kelly, L.J., Kesanakurti, P.R., Kim, J.S., Kim, Y.-D., Lahaye, R., Lee, H.-L., Long, D.G., Madriñán, S., Maurin, O., Meusnier, I., Newmaster, S.G., Park, C.-W., Percy, D.M., Petersen, G., Richardson, J. E., Salazar, G.A., Savolainen, V., Seberg, O., Wilkinson, M.J., Yi, D.-K., Little, D.P., 2009. A DNA barcode for land plants. Proc. Natl. Acad. Sci. 106 (31), 12794-12797.

Hollingsworth, P.M., Graham, S.W., Little, D.P., 2011. Choosing and using a plant DNA barcode. PLoS One 6 (5), e19254.

Ivanova, N.V., Kuzmina, M.L., Braukmann, T.W.A., Borisenko, A.V., Zakharov, E.V., 2016. Authentication of herbal supplements using next-generation sequencing. PLoS One 11 (5), e0156426.

Kite, G.C., Veitch, N.C., Boalch, M.E., Lewis, G.P., Leon, C.J., Simmonds, M.S.J., 2009. Flavonol tetraglycosides from fruits of Styphnolobium japonicum (Leguminosae) and the authentication of Fructus Sophorae and Flos Sophorae. Phytochemistry 70 (6), 785-794.

Li, X., Yang, Y., Henry, R.J., Rossetto, M., Wang, Y., Chen, S., 2015. Plant DNA barcoding: from gene to genome. Biol. Rev. 90 (1), 157-166.

Little, D.P., 2014. Authentication of Ginkgo biloba herbal dietary supplements using DNA barcoding. Genome 57 (9), 513-516.

Liu, Y., Wang, X.-Y., Wei, X.-M., Gao, Z.-T., Han, J.-P., 2018. Rapid authentication of Ginkgo biloba herbal products using the recombinase polymerase amplification assay. Sci. Rep. 8 (1), 8002.

Ma, Y.C., Mani, A., Cai, Y.L., Thomson, J., Ma, J., Peudru, F., Chen, S., Luo, M., Zhang, J. Z., Chapman, R.G., Shi, Z.T., 2016. An effective identification and quantification method for Ginkgo biloba flavonol glycosides with targeted evaluation of adulterated products. Phytomedicine 23 (4), 377-387.

Pawar, R.S., Handy, S.M., Cheng, R., Shyong, N., Grundel, E., 2017. Assessment of the Authenticity of herbal dietary supplements: comparison of chemical and DNA barcoding methods. Planta Med. 83 (11), 921-936.

Soares, S., Amaral, J.S., Oliveira, M.B.P.P., Mafra, I., 2015. Improving DNA isolation from honey for the botanical origin identification. Food Control 48, 130-136.

Techen, N., Parveen, I., Pan, Z., Khan, I.A., 2014. DNA barcoding of medicinal plant material for identification. Curr. Opin. Biotechnol. 25, 103-110.

Villa, C., Costa, J., Oliveira, M.B.P.P., Mafra, I., 2017. Novel quantitative real-time PCR approach to determine safflower (Carthamus tinctorius) adulteration in saffron (Crocus sativus). Food Chem. 229, 680-687.

WHO, 2004. New WHO Guidelines to Promote Proper Use of Alternative Medicines. Retrieved January 4, 2021 from: https://www.who.int/mediacentre/news/releases/ 2004/pr44/en/.

Wohlmuth, H., Savage, K., Dowell, A., Mouatt, P., 2014. Adulteration of Ginkgo biloba products and a simple method to improve its detection. Phytomedicine 21 (6), 912-918.

Yao, H., Song, J., Liu, C., Luo, K., Han, J., Li, Y., Pang, X., Xu, H., Zhu, Y., Xiao, P., Chen, S., 2010. Use of ITS2 region as the universal DNA barcode for plants and animals. PLoS One 5 (10), e13102. 